\title{
ГЕОЭКОЛОГИЧЕСКАЯ ОЦЕНКА ТЕРРИТОРИИ РАСПОЛОЖЕНИЯ ГАЗОКОМПРЕССОРНОЙ СТАНЦИИ КС-11 СИНДОРСКОГО ЛИНЕЙНО-ПРОИЗВОДСТВЕННОГО УПРАВЛЕНИЯ МАГИСТРАЛЬНЫХ ГАЗОПРОВОДОВ
}

\author{
Н. Ю. Мачулина, К.А. Седрисев \\ Ухтинский государственный технический университет, Ухта, Россия \\ Поступила в редакиию 23 апреля 2019 г.
}

\begin{abstract}
Аннотация: В статье представлены результаты геоэкологической оценки состояния компонентов окружающей среды территории расположения газокомпрессорной станции КС-11 Синдорского линейно-производственного управления магистральных газопроводов (ЛПУМГ). Оценка, выполненная на основе результатов количественного химического анализа проб поверхностных и подземных вод, донных отложений и почв, помогла установить наличие загрязнений в реке около КС-11 (a также то, насколько давно они произошли), в подземных водах рядом с промплощадками и отсутствие загрязнений в почвах. Изучение особенностей функционирования газокомпрессорных станций и геохимических особенностей таежной зоны позволило определить причины загрязнений и отнести часть из них к антропогенным, а другую часть - к вызванным природными особенностями рассматриваемой территории. На основе результатов оценки предложены меры, которые помогут снизить техногенное влияние на воды территории.
\end{abstract}

Ключевые слова: геоэкология, газокомпрессорная станция, загрязнение, российский Север, предельно-допустимая концентрация.

\section{Geoecological assessment of the location of the gas compressor station KS-11 of the Sindorsky linear production department of gas pipelines}

\section{N. Yu. Machulina, K. A. Sedrisev}

\begin{abstract}
The article describes the results of geoecological evaluation of the surface water and groundwater, bottom sediments and soils state on the gas compressor station KS-11 of Sindorsky line pipe operation center (LPOC) territory. The performed evaluation was based on the results of the quantitative chemical analysis. The evaluation has helped to clarify the pollution of the river near KS-11 (and how long has it been occurred), in groundwater near industrial sites and the absence of pollution in the soils. Learning functional features of gas compressor stations and geochemical features of the taiga zone has allowed to determine the pollution causes and to attribute one part to the artificially caused pollution and the other part to the natural caused pollution. Based on the evaluation results, measures have been proposed that will help to reduce the technical impact on the country.
\end{abstract}

Key words: geoecology, gas compressor station, pollution, Russian North, maximum allowable concentration.

\section{ВВЕДЕНИЕ}

Антропогенная деятельность в области добычи и переработки полезных ископаемых широко распространена по всему миру. Наиболее важными ископаемыми являются те, что обеспечивают техносферу топливом и энергией - это нефть и при-

() Мачулина Н.Ю., Седрисев К.А., 2019

Материал статьи доступен по лицензии Creative Commons "Attribution" 4.0 родный газ. В России наибольшие объемы добычи и переработки данных видов ресурсов сосредоточены в северных широтах.

Российский Север - это обширные пространства от Карелии до Камчатки. С одной стороны, они богаты природными ресурсами и выполняют важные экосистемные функции, с другой - имеют малую экологическую емкость. Низкое видовое разнообразие вкупе с низкой биологической про- 
дуктивностью и обедненностью трофических связей говорит о крайней важности наблюдений за состоянием окружающей среды в данном регионе [3].

На сегодняшний день самым перспективным ресурсом, добываемом на Российском Севере, является природный газ. Экспорт природного газа, а также налоговые отчисления добывающих компаний приносят ощутимые поступления в бюджет государства. Природный газ - это самое чистое в экологическом отношении топливо: при его добыче и использовании оказывается меньшее (в сравнении с нефтью) негативное влияние на компоненты окружающей среды. Однако транспорт и переработка газа могут сопровождаться рядом отрицательных воздействий на атмосферу, гидросферу, почвенный покров.

Республика Коми - один из ключевых форпостов газовой промышленности. Здесь проходит газопровод «Сияние севера», вдоль которого расположено несколько компрессорных станций, а также газоперерабатывающий завод - все они относятся к ПАО «Газпром».

Индикатором геоэкологического состояния территории и степени антропогенного воздействия служит химический состав проб компонентов окружающей среды. В ходе полевых исследований, приуроченных к инженерно-экологическим изысканиям, в составе группы специалистов отдела экологической безопасности научного центра ПАО «Газпром» (филиал ВНИИГАЗа в г. Ухта) были отобраны пробы поверхностных вод, включая донные отложения, подземных вод и почв в районе расположения одной из компрессорных станций КС-11 Синдорского линейно-производственного управления магистральных газопроводов (ЛПУМГ). По окончанию полевых исследований в научном центре был проведен количественный химический анализ отобранных проб. На основе данных анализа и нормативно-правовой документации была выполнена геоэкологическая оценка территории расположения КС-11, выявлены негативные последствия производственной деятельности, а также определены возможные причины сложившейся ситуации и разработаны рекомендации по ее улучшению.

\section{МЕТОДИКА ЭКСПЕРИМЕНТА}

Наиболее корректным методом оценки геоэкологического состояния территории является сравнение фактических концентраций химических элементов в пробах с их фоновыми концентрациями. Однако в данном случае из-за отсутствия необхо- димой информации фактические концентрации сравнивались с предельно допустимыми (ПДК). ПДК - максимальная концентрация химических веществ в окружающей среде, которая при повседневном влиянии на организм в течение длительного времени не вызывает патологических изменений или заболеваний [1]. Из определения следует, что, узнав, какую долю ПДК составляет концентрация того или иного вещества, можно сделать предварительные выводы о сложившейся геоэкологической обстановке. Источниками информации о ПДК послужили нормативно-правовые акты в области охраны окружающей среды: приказ Министерства сельского хозяйства РФ от 13 декабря 2016 года № 552 - «Об утверждении нормативов качества воды водных объектов рыбохозяйственного значения, в том числе нормативов предельно допустимых концентраций вредных веществ в водах водных объектов рыбохозяйственного значения», СанПиН 2.1.4.1074-01, СанПин 2.1.5.980-00, ГН 2.1.5.1315-03, ГН 2.1.7.2041-06, ГН 2.1.7.2511-09, письмо Минприроды России от 27.12.1993 N 04-25/61-5678 «О порядке определения размеров ущерба от загрязнения земель химическими веществами».

Для составления целостной геоэкологической картины необходимо иметь информацию физикогеографического характера об исследуемой местности. Компрессорная станция расположена в пределах Западно-Предтиманской пологоволнистой аккумулятивной и озерно-аллювиальной равнины на относительно приподнятой возвышенности, ориентированной в меридиональном направлении с пологими склонами. Единственной рекой, протекающей через санитарно-защитную зону компрессорной станции, является Симва - приток реки Вис. Общая протяженность Симвы - 25 км. Превышение восточной части возвышенности относительно уреза водотока - 16 м, западной - менее 5 м, южной и северной - более 10 м. Водоток имеет 10 притоков длинной менее 10 км общей протяженностью 30 км. Вместе с ними он относится к бассейну Северной Двины, а в его составе к крупному Вымскому водосбору. Водосборы водотоков представляют собой многоуровневую каскадную систему с окончательным сбросом веществ в реку Иоссер, далее в реку Вымь, после - в Вычегду, затем - в Северную Двину. Что касается почвенногрунтового состава, то изучаемый район находится на песчано-супесчаных подстилаемых моренными суглинками торфяно-подзолисто-глеевых и иллювиально-гумусовых почвах. 
Все пробы почв, донных отложений, поверхностных и подземных вод были отобраны в районе расположения КС-11. Пробы поверхностных вод изъяты из двух точек на реке Симва (№ 1C) в границах санитарно-защитной зоны (С33), № 2C - за пределами СЗ3, вниз по течению. Пробы донных отложений (№ 1Сд, № 2Сд) были отобраны рядом с № 1С и № 2С соответственно. Шесть проб почв (№ 2Сп, № 3Сп, № 5Сп, № 6Сп, № 7Сп, № 8Сп) и две пробы подземных вод (№ 3С, №4С) извлечены в непосредственной близости от производственных объектов компрессорной станции. Остальные пробы почв (№ 1Сп, № 4Сп) отобраны на границе С33. Пробы поверхностных вод анализировались по тридцати показателям, донных отложений - по девяти, подземных вод - по семнадцати, почв - по двенадцати.

\section{ОБСУЖДЕНИЕ РЕЗУЛЬТАТОВ}

При оценке загрязнения поверхностных вод критерием служили величины ПДК веществ в воде рыбохозяйственного назначения (ПДК $/$ $/ x$. Во всех пробах не превышают нормативных значений концентрации взвешенных веществ, основных ионов, нитритов, нитратов, ионов аммония, фосфатов, анионных поверхностно активных веществ, нефтепродуктов, никеля, кадмия, мышьяка и марганца, величина сухого остатка. По результатам исследования воды можно отнести к очень мягким гидрокарбонатным натриевого типа. Они являются маломинерализованными (до 200 мг/дм³), слабокислыми ( $\mathrm{pH} \approx 6,3-6,4)$. Превышение хозяйственно-питьевого норматива по химическому потреблению кислорода (ХПК) в 2,6 раза свидетельствует о быстром расходовании кислорода. Причиной может служить большое количество органического вещества, характерное для поверхностных вод таежной зоны, а также возможное влияние жилой зоны, расположенной выше по течению.

В пробах зафиксированы превышения ПДК содержанию тяжелых металлов. Многократное превышение зафиксировано по меди - в пробах № 1С и № 2C. Ее содержание составило соответственно 34 и 140 ПДК. Такая вода пригодна к употреблению человеком, (ПДК $(\mathrm{Cu})$ для хозяйственно-питьевого использования $=1$ мг/дм $\left.{ }^{3}\right)$, но для водных организмов она губительна $\left(П Д К(\mathrm{Cu})_{\mathrm{p} / \mathrm{x}}=0,001 \mathrm{мг} /\right.$ дм$\left.^{3}\right)$. Содержание цинка в пробах превысило ПДК в 3 раза. Цинк и медь в повышенных концентрациях разрушают слизистую оболочку кишечника у рыб [2]. Повышенные концентрации цинка и меди могут быть обуслов- лены естественными геохимическими процессами. Однако более вероятно, что приведшее к чрезвычайно опасной ситуации на одном из участков реки загрязнение имеет антропогенное происхождение. Концентрация свинца в двух пробах также превышает ПДК ${ }_{\mathrm{p} / \mathrm{x}}$ в 3 раза. В некоторых случаях свинец поступает в поверхностные воды при растворении минералов (галенит, англезит, церуссит), но они распространены только в районе приполярного Урала, поэтому наиболее вероятным источником загрязнения является или жилая зона, или производственная площадка - поступление в реку отходов от автомобильных аккумуляторов. Высокое содержание железа вызвано природными особенностями исследуемого района - миграцией железа из почв в поверхностные воды, т.е. загрязнение носит естественный характер и не связано с влиянием стоков КС-11.

Относительно превышений по содержанию ртути однозначных выводов сделать не удалось из-за недостаточной чувствительности использованной методики: ее предел обнаружения 0,00004 мг/дм ${ }^{3}$, a ПДК $(\mathrm{Hg})_{\mathrm{p} / \mathrm{x}}-0,00001$ мг/дм ${ }^{3}$, т. е. в 4 раза ниже.

Содержание фенолов в пробе № 1C, отобранной внутри С33, выше по течению относительно цехов КС, превышает норму в десятки раз (49 ПДК p/x $_{\text {) }}$; в то же время в пробе № 2C, отобранной за пределами С33 ниже по течению, их концентрация ниже предела обнаружения (менее 0,5 ПДК $\mathrm{p/x}$. Высокая концентрация фенолов может быть обусловлена природными факторами - разложением древесины, содержащей до 40 \% лигнина. В 5 км от точки отбора пробы № 1С вверх по течению реки Симвы находится лесосека. Брошенные на месте рубок горы веток и древесной щепы (особенно в водоохранной зоне) гниют, в процессе гниения выделяются фенолы, попадающие затем в реку. Источниками загрязнения поверхностных вод фенолами могут быть как промышленные предприятия, так и жилая зона. Следовательно, большая разница в содержании фенолов в двух пробах может объясняться возможностью залпового сброса фенолов.

Также в двух пробах обнаружено пятикратное превышение ПДК ${ }_{p / x}$ по фторид-иону, явно имеющее техногенное происхождение.

Все водные объекты подразделяются на классы. Принадлежность к определенному классу качества помогает определить степень загрязнения водоема. Класс определяется с помощью индекса загрязненности воды (ИЗВ): 


$$
\text { ИЗВ }=\frac{1}{n} \cdot \sum_{i=1}^{n}\left(\frac{C_{i}}{\Pi Д \kappa_{i}}\right),
$$

где $C_{i}$ - концентрация компонента, мг/дм ${ }^{3} ; n-$ число показателей, используемых для расчета индекса; ПДК - установленный норматив для соответствующего типа водного объекта, мг/дм³ ${ }^{3}$ В зависимости от величины ИЗВ выделяют семь классов качества вод, каждому из которых соответствует определенный диапазон значений ИЗВ: от I (менее 0,2 ) - очень чистые до VII (более 10) - чрезвычайно грязные.

Предварительные расчеты ИЗВ для реки Симвы, как рыбохозяйственного водного объекта, показали, что поверхностные воды в зоне расположения КС-11 чрезвычайно грязные, т. е. относятся к VII классу. ИЗВ в обеих пробах больше 10, и проба № 2С загрязнена сильнее.

Для более точной оценки загрязнения поверхностных вод необходимо изучение химического состава донных отложений. Сравнение фактических концентраций одних и тех же веществ в системе «вода - донные отложения» позволяет определить, является ли загрязнение хроническим, или же оно появилось относительно недавно. Для этого используется коэффициент донной аккумуляции (КДА):

$$
\kappa Д A=\frac{C_{\partial o}}{C_{\text {вод }}},
$$

где $C_{\partial о}$ - концентрация загрязняющего вещества в донных отложениях в створе, мг/дм ${ }^{3} ; C_{\text {вод }}-$ концентрация загрязняющего вещества в воде в ствоpe, мг/дм ${ }^{3}$.

Полученные в результате расчета КДА значения группируются в зависимости от своей величины: значения от 0 до 9 характеризуют обстановку в водном объекте как относительно удовлетворительную, без признаков хронического загрязнения; от 10 до 999 - указывают на поступление в водный объект свежего загрязнения; от 1000 и выше - свидетельствуют о высоком уровне хронического загрязнения водного объекта.

В данном случае низкие концентрации тяжелых металлов в донных отложениях и недостаточная чувствительность используемых методик не позволяют сделать определенных выводов о наличии и динамике загрязнения. Однако КДА нефтепродуктов в пробах № 1Сд и № 2Сд был рассчитан и составил, соответственно, 140 и 226, что указывает на свежее техногенное загрязнение (по- ступление веществ в реку произошло сравнительно недавно).

При оценке загрязнения подземных вод критерием служили величины ПДК веществ в воде хозяйственно-питьевого и культурно-бытового назначения (ПДК $)$. В целом подземные воды изучаемого района загрязнены в меньшей степени, чем поверхностные - и это при том, что пробы были отобраны в непосредственной близости от цеха № 4. В обеих пробах концентрации хлоридов, сульфатов, нитратов, АПАВ, Cu, Zn, Ni, Cd, Hg, As, а также сухой остаток, водородный показатель и жесткость находятся в пределах нормы. Концентрация свинца в обеих пробах превышает ПДК в 4 раза; по сравнению с поверхностными водами, в подземных водах его в 2,5 раза больше - происходит миграция свинца из грунта в водоток.

В пробе № 3С отмечено повышенное содержание нефтепродуктов, железа и марганца. Высокое содержание $\mathrm{Fe}$ и $\mathrm{Mn}$ характерно как для поверхностных, так и для подземных вод таежной зоны. Загрязнение же нефтепродуктами (2,6 ПДК) обусловлено техногенным воздействием: утечками ГСМ автотранспорта, последствиями эксплуатации компрессорной станции. Точки отбора проб находятся сравнительно близко друг от друга, на расстоянии не более 150 м. При этом в пробе № 3С по сравнению с пробой № 4С содержание марганца выше, как минимум в 300 раз, железа и нефтепродуктов - в 8 раз. Такие «разбросы» на столь коротком отрезке могут быть вызваны либо локальностью загрязнения, либо относительно недавним поступлением веществ в грунт.

Почвы оказались самым чистым компонентом окружающей среды в районе расположения КС-11: содержание всех исследованных компонентов в них намного ниже ПДК

\section{ЗАКЛЮЧЕНИЕ}

Таким образом, проведенная геоэкологическая оценка выявила проблемы с загрязнением окружающей среды в районе КС-11 и позволила понять причины превышения допустимых норм. Поскольку самым загрязненным компонентом оказались поверхностные воды, необходимы мероприятия по снижению стоков с промплощадок КС. Например, возведение защитных сооружений с целью локализации загрязнений (которые могут возникнуть в результате аварийных и других нештатных ситуаций); осуществление сбросов вод после гидравлических испытаний трубопроводов только в систему водоотведения. Также, для более объектив- 
Геоэкологическая оценка территории расположения газокомпрессорной станции КС-11 Синдорского линейнопроизводственного управления магистральных газопроводов

ной оценки антропогенного влияния, необходимо отбирать пробы не только на реке Симве, но и в дренажных ручьях, идущих в реку от компрессорной станции, а также дополнить перечень анализов поверхностных вод определением БПК 5 и растворенного кислорода.

Использованный метод сравнения фактических концентраций с ПДК помог выполнить геоэкологическую оценку территории, однако он не позволил сделать точных выводов о природе тех или иных загрязнений, т.к. ПДК - это общие санитарно-гигиенические нормативы, не отражающие ландшафтно-геохимических особенностей данного региона.

С целью исправления сложившейся ситуации в Республике Коми (и других регионах, где ведется интенсивная деятельность по добыче и переработке нефти и газа) необходимо провести работы, направленные на определение фоновых концентраций химических веществ в различных группах природных ландшафтов (т. е. ландшафтов со сходными геохимическими и физико-географическими особенностями). На федеральном уровне должны быть приняты нормативно-правовые документы, дополняющие существующие СНиПы, СанПиНы, и ГНы этими фоновыми концентрациями, а также иной информацией, указывающей на местные природные особенности.

Для определения природы тех или иных загрязнений нужно дополнительное изучение проек-

Мачулина Наталья Юрьевна старший преподаватель Ухтинского государственного технического университета, E-mail: nmachulina66@ gmail.com Седрисев Кирилл Алексеевич студент Ухтинского государственного технического университета (направление обучения «экология и природопользование»), E-mail: k.sedrisev@ yandex.ru тов допустимых выбросов и нормативно допустимых сбросов предприятия, нормативов образования отходов и лимитов на их размещение.

\section{СПИСОК ЛИТЕРАТУРЫ}

1. Предельно допустимая концентрация // Академик - URL: https:// dic.academic.ru/ dic.nsf/ruwiki/50465 (дата обращения 14.02.2019).

2. Ушакова Н. В. Влияние тяжелых металлов (цинк, медь), температуры и $\mathrm{pH}$ на активность протеиназ рыб и их потенциальных объектов питания : автореф. дис. ... канд. биол. наук / Н. В. Ушакова. - Борок, 2009.

3. Шадрина Е. Г. Биоиндикация воздействия горнодобывающей промышленности на наземные экосистемы Севера : дис. ... д-ра биол. наук / Е. Г. Шадрина. Якутск, 2004.

\section{REFERENCES}

1. Predel'no dopustimaya kontsentratsiya [Maximum allowable concentration]. Akademik, Available at: https:// dic.academic.ru/ dic.nsf/ruwiki/50465 (accessed 14 February 2019).

2. Ushakova N. V., Vliyanie tyazhelykh metallov (tsink, med'), temperatury i $\mathrm{pH}$ na aktivnost' proteinaz ryb i ikh potentsial'nykh ob"ektov pitaniya [The influence of heavy metals (zinc, copper), temperature and $\mathrm{pH}$ on the activity of fish proteinases and their potential food objects]. Borok, 2009.

3. Shadrina E. G., Bioindikatsiya vozdeystviya gornodobyvayushchey promyshlennosti na nazemnye ekosistemy Severa [Bioindication of the impact of mining on terrestrial ecosystems of the North]. Yakutsk, 2004.

Machulina Natalya Yuryevna

Senior lecturer of Ukhta State Technical University, E-mail: nmachulina66@gmail.com

Sedrisev Kirill Alekseevich

Third-year student of Ukhta State Technical University (course «ecology and environmental management»), E-mail: k.sedrisev@yandex.ru 